\title{
Evaluation of apoptosis markers in different cell lines infected with equine arteritis virus
}

\author{
GE Metz @i, MA Abeyá, MS Serena, CJ Panei, and MG Echeverría
}

Department of Virology, Faculty of Veterinary Sciences, National University of La Plata, La Plata, Argentina

ABSTRACT

Equine arteritis virus (EAV) induces apoptosis in infected cells. Cell death caused by EAV has been studied mainly using three cell lines, BHK-21, RK-13 and Vero cells. The mechanism of apoptosis varies among cell lines and results cannot be correlated owing to differences in EAV strains used. We evaluated different markers for apoptosis in BHK-21, RK-13 and Vero cell lines using the Bucyrus EAV reference strain. Acridine orange/ethidium bromide staining revealed morphological changes in infected cells, while flow cytometry indicated the extent of apoptosis. We also observed DNA fragmentation, but the DNA ladder was detected at different times post-infection depending on the cell line, i.e., 48, 72 and $96 \mathrm{~h}$ post-infection in RK-13, Vero and BHK-21 cells, respectively. Measurement of viral titers obtained with each cell line indicated that apoptosis causes interference with viral replication and therefore decreased viral titers. As an unequivocal marker of apoptosis, we measured the expression of caspase- 3 and caspases- 8 and -9 as extrinsic and intrinsic markers of apoptosis pathways, respectively. Caspase-8 in BHK-21 cells was the only protease that was not detected at any of the times assayed. We found that Bucyrus EAV strain exhibited a distinctive apoptosis pathway depending on the cell line.

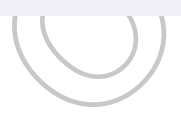

20 The order, Nidovirales, comprises the families, Arteriviridae, Coronaviridae, Mesoniviridae and Roniviridae (de Groot et al. 2012; Lauber et al, 2012). Equine arteritis virus (EAV) is the prototype member of the family Arteriviridae. It is a member of the new genus, Equarterivirus (Kuhn et al. 2016), and four other genera, Diparterivirus, Nesarterivirus, Porarterivirus and Simarterivirus) include the porcine reproductive and respiratory syndrome virus (PRRSV), simian hemorrhagic fever virus (SHFV), lactate dehydrogenase-elevating virus (LDV), the recently recognized wobbly possum disease virus (WPDV) and eleven simian arteriviruses (Dunowska et al. 2012; Snijder et al. 2013). EAV is a small enveloped virus with a $12.7 \mathrm{~kb}$ positive-sense single stranded RNA genome that includes ten functional open reading frames (Snijder and Meulenberg 1998).

Apoptosis is the mechanism by which cells undergo systematic self-destruction in response to a variety of stimuli including viral infection. This mechanism could limit the time and the cellular machinery available for virus replication. Therefore, some viruses have evolved mechanisms to evade cellular apoptosis to establish and maintain viral persistence, whereas other viruses promote apoptosis and benefit from cell death (Nakamura-López et al. 2011).
Morphological and molecular features participate in apoptosis. Cell shrinkage, membrane blebbing, chromatin cleavage, nuclear condensation and formation of pyknotic bodies of condensed chromatin are the main characteristics of apoptosis of cultured cells (Häcker 2000).

DNA fragmentation, which is induced by apoptotic stimuli such as viral infections, is a characteristic of apoptosis. Apoptosis is highly regulated and controlled by the family of cysteinyl aspartate-specific proteases (caspases) (Kitazumi and Tsukahara 2011). Caspases catalyze key steps in apoptosis by cleaving several effectors of the mechanism. One molecular feature that characterizes apoptosis is the activation of executioner caspase-3. Activation of caspase- 9 is an indicator of the intrinsic mechanism of apoptosis, whereas activation of capase- 8 characterizes the extrinsic mechanism of apoptosis (Elmore 2007).

Infection of different cell lines with EAV causes activation of apoptosis. Infection of African green monkey kidney cells (Vero) with EAV induces apoptosis after $24 \mathrm{~h}$ (Archambault and St-Laurent 2000), which was initiated by caspase-8 and caspase-9 activation (St-Louis and Archambault 2007). EAV infection in rabbit kidney cells (RK-13) also activates both caspases (Metz et al. 2016), whereas in baby hamster kidney cells (BHK-21), EAV 
infections induce only caspase-9 activation (Cholleti et al. 2013). All these results indicated apoptosis induction in diverse cell line using different EAV strains.

Control of apoptosis is affected significantly by EAV. Differential induction of apoptosis has been observed in reovirus (Tyler et al. 1995; Rodgers et al. 1997), Theiler's murine encephalomyelitis virus (Jelachich et al. 1996) and influenza virus (Price et al. 1997). On the other hand, only the attenuated and nonpathogenic strain of rabies virus induces caspase-dependent apoptosis in human cells (Préhaud et al. 2003).

Different viral strains have been used to study EAV induced apoptosis: EAV pathogenic (SP3A and Bucyrus) and nonpathogenic (T1329 and Arvac) strains (Archambault and St-Laurent 2000; St-Louis and Archambault 2007; Cholleti et al. 2013). Owing to the different cell lines used by these investigators, results are difficult to interpret and it is difficult to draw clear conclusions. Therefore, we investigated morphological and biochemical features of apoptosis using the reference and pathogenic EAV strain, and BHK-21, RK-13 and Vero cell lines.

\section{Material and methods}

\section{Cell lines and virus strain}

We investigated three cell lines: BHK-21, RK-13 and Vero cells (ABAC, Argentine Cell Bank Association Buenos Aires, Argentina). All cell lines were grown in minimum essential medium (MEM) (Gibco, Invitrogen, Carlsbad, CA), supplemented with $2 \mathrm{mM}$ glutamine (Gibco, Invitrogen), $100 \mathrm{IU} / \mathrm{ml}$ penicillin and $10 \%$ fetal calf serum (FCS) that was reduced to $2 \%$ for cell maintenance. An $80 \%$ confluent cell monolayer was used for all experiments.

100 The EAV Bucyrus strain (PubMed Reference: DQ846750) was titered using the end point dilution assay for each cell line and used at a multiplicity of infection (MOI) of five for all assays. EAV infected cells were incubated at $37{ }^{\circ} \mathrm{C}$ in a $5 \% \mathrm{CO}_{2}$ incubator and 105 samples were taken from 24 to $96 \mathrm{~h}$ post-infection depending on the experiment.

\section{Morphological study of apoptotic cells using acridine orange (AO)/ethidium bromide (EB) staining}

110 Coverslips, $18 \times 18 \mathrm{~mm}$, were placed in a $3.5 \mathrm{~cm}$ diameter petri dish, seeded with $10^{6}$ cells of each cell line culture and infected with the EAV Bucyrus strain at MOI 5. Infected cells were incubated as described above, then each coverslip was washed with phosphate-buffered saline
MO) (Kasibhatla et al. 2006). Uninfected culture cell monolayers were used as negative controls and cultures where apoptosis was induced using $1 \mu \mathrm{g} / \mathrm{ml}$ staurosporine (Santa Cruz Biotechnology, Santa Cruz, CA) were used as positive controls. All tests were performed in duplicate.

A 1:10 dilution of a solution of $100 \mathrm{mg} / \mathrm{ml} \mathrm{AO}$ and $100 \mathrm{mg} / \mathrm{ml} \mathrm{EB}$ in PBS was added to each coverslip for $2 \mathrm{~min}$, then the solution was removed and coverslips were mounted on a clean microscope slide and examined by fluorescence microscopy (Model BHS; Olympus System Microscope, Bio Analítica, Buenos Aires, Argentina).

\section{Apoptosis detection using annexin $V$ and propidium iodide (PI) by flow cytometry}

A monolayer of each cell line grown in 6-well plates at $80 \%$ confluence was infected and incubated as described above. Positive and negative controls were as described above. Both floating and trypsinized adherent cells were washed with PBS and collected by centrifugation at $250 \mathrm{x}$ $\mathrm{g}$ for $5 \mathrm{~min}$. All cells were re-suspended in $200 \mu \mathrm{l}$ Annexin V-binding buffer containing PI (Sigma Aldrich), $10 \mu \mathrm{g} / \mathrm{ml}$ and $10 \mu \mathrm{l}$ FITC-Annexin $\mathrm{V} / \mathrm{ml}$ (Immuno Tools, Friesoythe, Germany). After incubation in the dark for 10 min, fluorescence signals of FITC-Annexin V and PI were detected using a fluorescence activated cell sorter (FACScan, Instituto de Estudios Inmunológicos y Fisiopatológicos, FCE-UNLP-CONICET). Cell debris was excluded from analysis using the conventional scatter gating method. For each sample, 10,000 events were analyzed using the FlowJo software system.

\section{DNA fragmentation in EAV infected cell cultures}

A monolayer of each cell line grown in T-25 cell culture flasks at $80 \%$ confluence was infected with the EAV Bucyrus strain at MOI 5. The appearance of cytopathology and the concomitant lysis of cells were manifested at different hours post-infection (hpi) depending on the cell line used. Uninfected culture cell monolayers were used as negative controls.

DNA was extracted from all samples using the phenol/ chloroform protocol. Briefly, cell pellets were washed and suspended in TEN buffer (100 mM Tris-HCl, $\mathrm{pH} 7.5$; $150 \mathrm{mM} \mathrm{NaCl} ; 12 \mathrm{mM}$ EDTA, $\mathrm{pH} 8.0$; and 1\% SDS). Then $0.2 \mathrm{mg} / \mathrm{ml}$ proteinase $\mathrm{K}$ was added and incubated at $50{ }^{\circ} \mathrm{C}$ for $4 \mathrm{~h}$. The lysate was extracted once with TE buffer (10 mM Tris- $\mathrm{HCl}$ and $1 \mathrm{mM}$ EDTA, $\mathrm{pH}$ 8.0), saturated phenol, and once with 25:24:1 phenol:chloroform:isoamyl alcohol. Finally, total DNA was precipitated with two volumes of $99 \%$ ethanol, rinsed twice with $70 \%$ ethanol, dried and dissolved in $40 \mu \mathrm{l}$ sterilized distilled water. Samples were run in a $1 \%$ agarose gel with a 100 
bp ladder (Promega, Madison, WI) and stained with ethidium bromide to visualize DNA fragmentation.

\section{Virus quantification}

Briefly, samples from EAV infected cultures were taken from 24 to 72 hpi for RK-13 and Vero cell lines and an additional sample at $96 \mathrm{hpi}$ for BHK-21cells. The viral titers were determined in quadruplicate using $50 \mu \mathrm{l}$ of sample by a statistical method (Reed and Muench 1938). The viral titers were expressed as the amount of virus that produced a cytopathic effect in the $50 \%$ of tissue cultures inoculated (TCID 50\%/50 $\mu$ l).

\section{Immunostaining of caspases-3, -8 and -9 with polyclonal antibodies}

We used the same methodology as described for morphological studies using AO/EB staining to detect activation of caspases. Coverslips with each EAV infected cell culture were incubated with different caspase antibodies: IgG goat polyclonal anti-caspase-3 (L-18), IgG goat polyclonal anti-caspase-8 (P-18) and IgG goat polyclonal anti-caspase-9 (P-10) (Santa Cruz Biotechnology) diluted 1:100 in PBS. The coverslips were washed twice with PBS, then incubated with the secondary antibody, IgG rabbit anti- goat conjugated with peroxidase (Sigma Aldrich) diluted 1:500. Recognition of the secondary antibody was visualized using amino ethyl carbazole (AEC) (Sigma Aldrich) and hydrogen peroxide. A solution of $3 \mathrm{mg}$ AEC dissolved in $750 \mu \mathrm{l} \mathrm{N}, \mathrm{N}$-dimethylformamide was added to $14.25 \mathrm{ml}$ acetate buffer $(21 \mathrm{ml} 0.1 \mathrm{~N}$ acetic acid and $79 \mathrm{ml}$ sodium acetate $0.1 \mathrm{~N}$ ) with $150 \mu \mathrm{l}$ hydrogen peroxide. This solution was added to each coverslip for $3 \mathrm{~min}$ and the reaction was stopped by adding PBS. Each coverslip was placed on a clean microscope slide and examined by inverted microscopy (Model BHS; Olympus).

\section{Results \\ Morphological signs of apoptosis in EAV infected cells using AO/EB staining}

Cell shrinkage, nuclear condensation and membrane blebbing were the most common features in the cell cultures at $24 \mathrm{hpi}$ in RK-13 and Vero cells. By contrast, these features began to appear consistently in BHK-21 at $48 \mathrm{hpi}$ (Figure 1). At longer times post-infection, these features wereless visible owing to detachment of cells due to lysis of infected cells. The orange labeling of EB characteristic of late apoptosis was detected in EAV-infected and staurosporine-induced apoptosis cell culture (positive control).
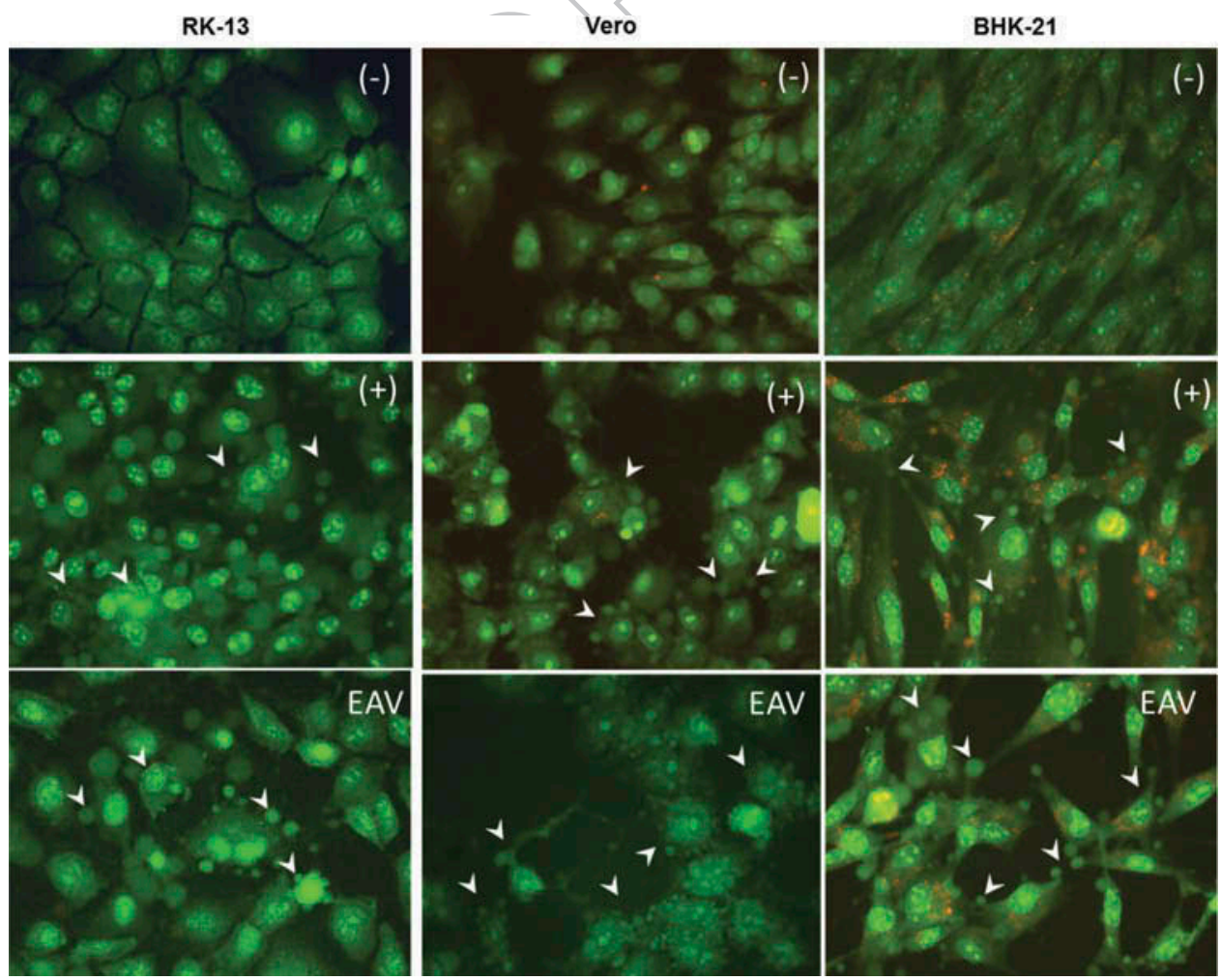

Figure 1. Confocal images of RK-13, Vero and BHK-21 cells stained with AO/EB at 48 hpi. (-) Uninfected cells (negative control); (+) staurosporine induced apoptotic cells (positive control); (EAV) EAV infected cells. Arrows indicate characteristic apoptotic bodies. $20 \mathrm{x}$ objective. 
We also detected some diffuse EB staining in the uninfected bhk-21 cell culture (negative control), but this was staining artifact.

\section{Apoptosis detection by flow cytometry}

To confirm the morphological signs of apoptosis using AO/EB staining, we analyzed all cell lines using flow cytometry under different conditions. We found that EAV induced apoptosis in RK-13 (Figure 2a), Vero (Figure 2b) and BHK-21 cell lines (Figure 2c). In Figure $2 \mathrm{~d}$, we show the percentage of apoptotic cells in each cell line at the different times assayed. We found that the characteristic apoptotic pattern was delayed in BHK-21 compared to the RK-13 and Vero cell lines. a)
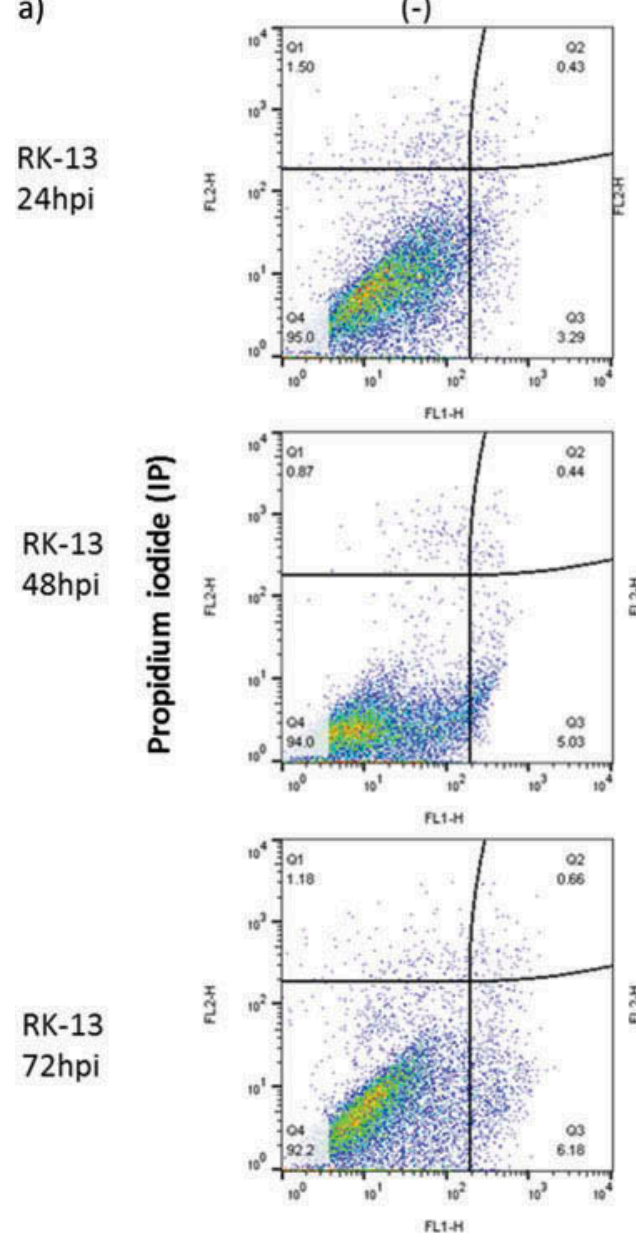

$\checkmark$
(+)
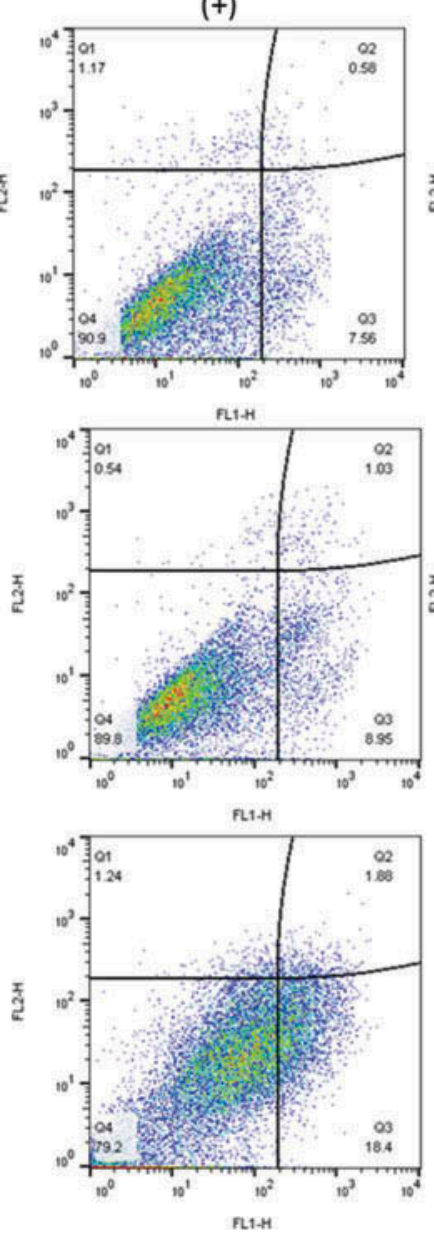

(EAV)
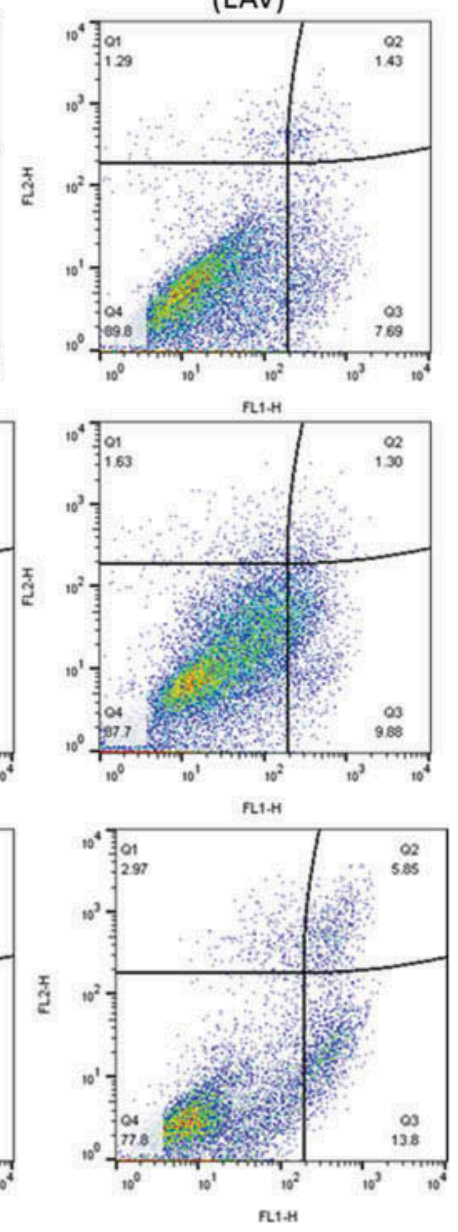

Figure 2. a) Apoptosis detection by flow cytometry with dual annexin V-PI cell labeling. RK-13 cells were infected with EAV at MOI 5. Uninfected culture and staurosporine induced apoptotic cells were used as negative and positive controls, respectively. Upper left quadrant (Q1), necrotic cells; upper right quadrant (Q2), late apoptotic and/or necrotic cells; lower left quadrant (Q3), intact cells; lower right quadrant (Q4) early apoptotic cells. The number in each quadrant refers to the percentage of cells in each subpopulation. The figure is representative of 10,000 cells analyzed independently in two experiments. b) Apoptosis detection by flow cytometry with dual annexin V-PI cell labeling Vero cells were infected with EAV at MOI 5. Uninfected culture and staurosporine induced apoptotic cells were used as negative and positive controls, respectively. Upper left quadrant (Q1), necrotic cells; upper right quadrant (Q2) late apoptotic and/or necrotic cells; lower left quadrant (Q3), intact cells; lower right quadrant (Q4), early apoptotic cells. The number in each quadrant refers to the percentage of cells in each subpopulation. The figure is representative of 10,000 cells analyzed independently in two experiments. c) Apoptosis detection by flow cytometry with dual annexin V-PI cell labeling. BHK21 cells were infected with EAV at MOI 5. Uninfected culture and staurosporine induced apoptotic cells were used as negative and positive controls, respectively. Upper left quadrant (Q1), necrotic cells; upper right quadrant (Q2), late apoptotic and/or necrotic cells; lower left quadrant (Q3), intact cells and lower right quadrant; (Q4) early apoptotic cells. The number in each quadrant refers to the percentage of cells in each subpopulation. The figure is representative of 10,000 cells analyzed independently in two experiments. d) Percentage of apoptotic cells measured by flow cytometry vs. post infection time of each cell line. 
b)
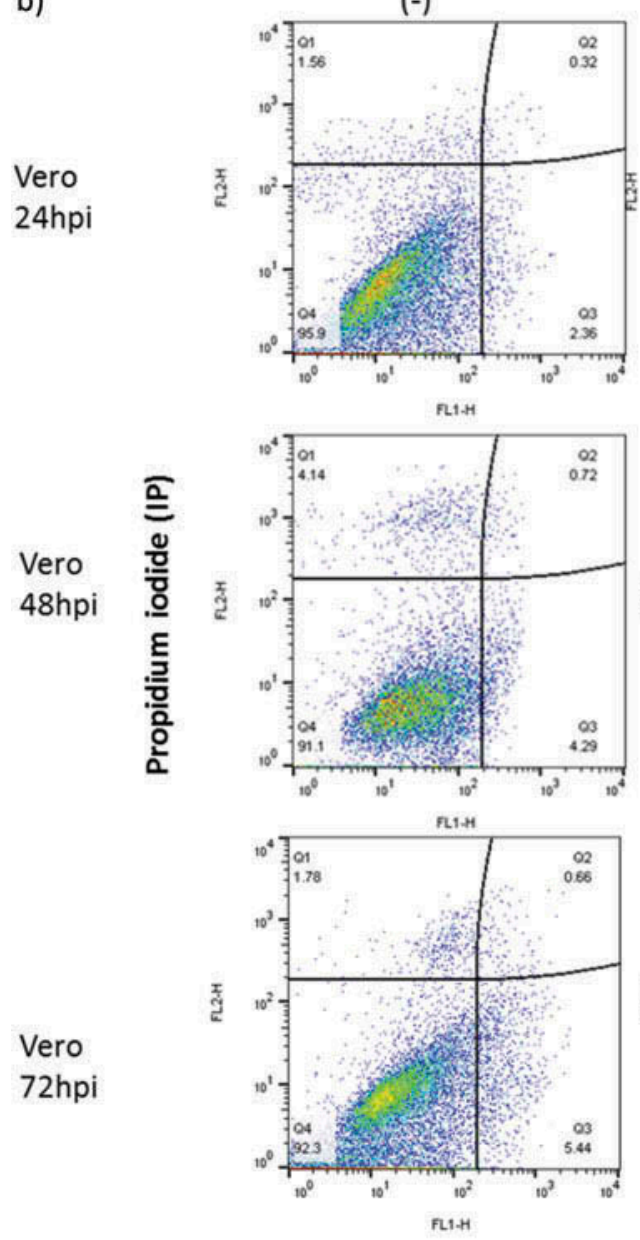

Figure 2. (Continued).

\section{DNA fragmentation in EAV infected cell cultures}

DNA fragmentation was detected in EAV infected cells in all three cell lines. Evidence of fragmentation was found at different post-infection times for each cell culture (Figure 3). For RK-13, the DNA ladder was detected at $48 \mathrm{hpi}$, in Vero at $72 \mathrm{hpi}$ and in BHK-21 cells at $96 \mathrm{hpi}$. Uninfected cells showed no evidence of fragmentation at the same assay times. Total cell lysis of the different EAV infected cells at MOI 5 was observed at $72 \mathrm{~h}$ for RK13, $96 \mathrm{~h}$ for Vero and $120 \mathrm{~h}$ for BHK-21; therefore, these times were not used for DNA extraction.

\section{EAV quantification}

Our quantification results are shown in Table 1. Infections at MOI 5 in each cell line exhibited the highest viral titer at 24 hpi: $10^{4.5}$ TCID $50 \% / 50 \mu \mathrm{l}$ for RK-13, $10^{5.8}$ TCID 50\%/50 $\mu$ l for Vero and $10^{6.5}$ TCID

$50 \% / 50 \mu \mathrm{l}$ for BHK-21.
Detection of caspases-3, -8 and -9 in situ by immunostaining

Activation of caspases was detected in each cell culture monolayer incubated with specific antibodies using AEC as chromogen. In EAV infected cells, an intense red staining indicated caspase- 3 staining at 24 and 48 hpi in all three cell lines (Figure 4a). Red staining also was detected in cells treated with staurosporine, a potent inducer of apoptosis in cell cultures. No AEC chromogen was detected in the cultures of uninfected cells. The same results were obtained using anti-caspase-9 (Figure 4b).

The extrinsic apoptosis mechanism was measured by activation of caspase- 8 in each culture. Caspase- 8 was detected in RK-13 and Vero cells at 24 and $48 \mathrm{hpi}$, but not in BHK-21 cells at any of the times assayed (24, 48, 72 and $96 \mathrm{hpi}$ ) (Figure 4c). The time course of caspase- 8 activation in BHK-21 cells is shown in Figure 5. 
c)
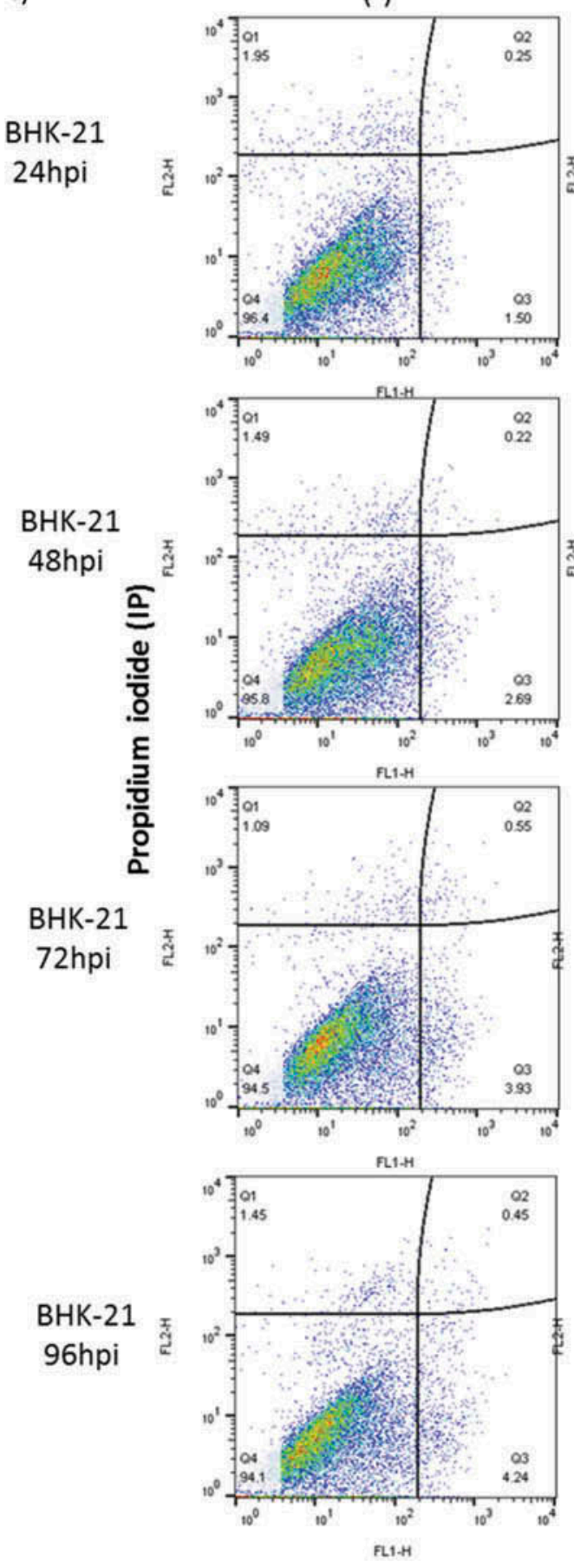

BHK-21 $96 \mathrm{hpi}$
(+)
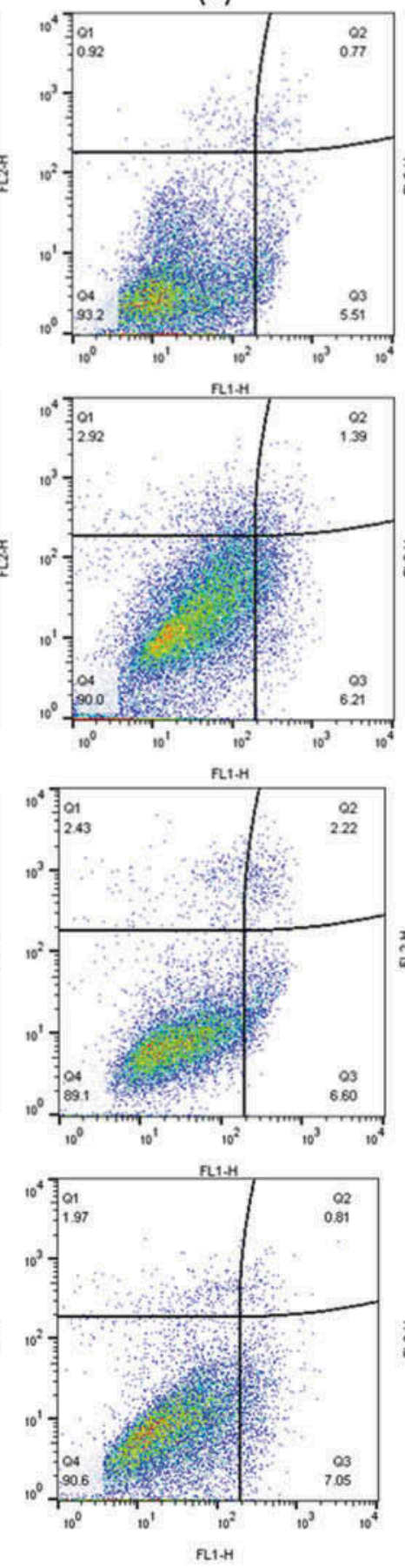

(EAV)
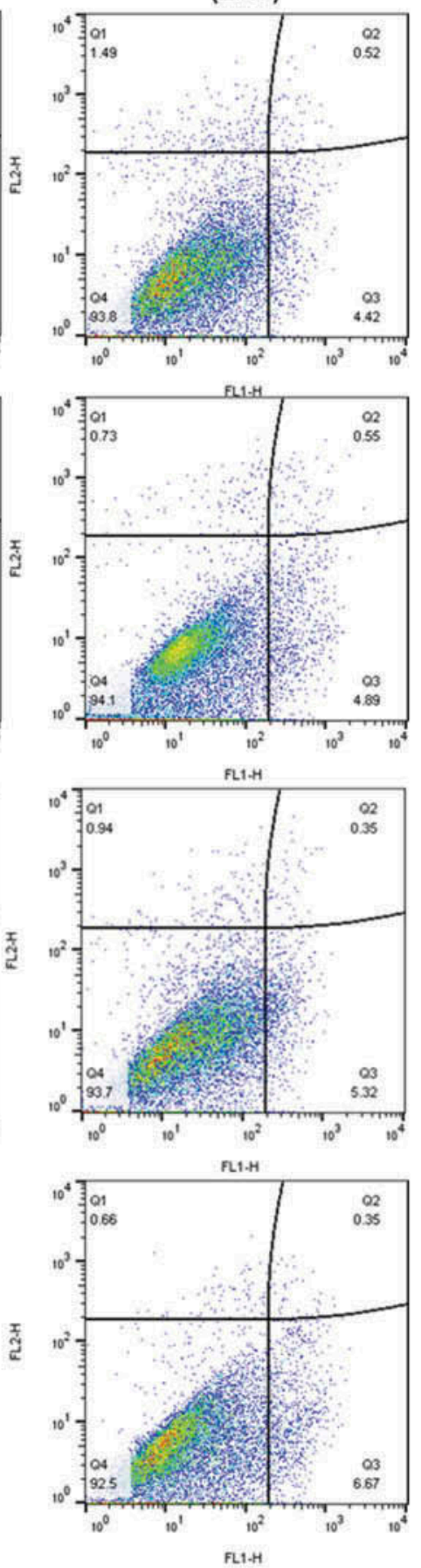

Anexxin V

Figure 2. (Continued).

\section{Discussion}

Cell infection by a virus elicits cellular responses designed to avoid the spread of viruses. Although earlier it had been assumed that apoptosis was initiated due to the response of the cell machinery to the infection, some viruses, especially RNA viruses, have been found to participate in initiation of this process (Thomson 2001).
EAV, a member of the Arteriviridae family, induces apoptosis in infected cells (Archambault and St-Laurent 2000). Although this mechanism has not been studied in vivo, it is thought that initiation of apoptosis participates in the pathogenesis in porarterivirus infections (Archambault and St-Laurent 2000; Suarez 2000; Miller and Fox 2004; Lee and Kleiboeker 2007). 


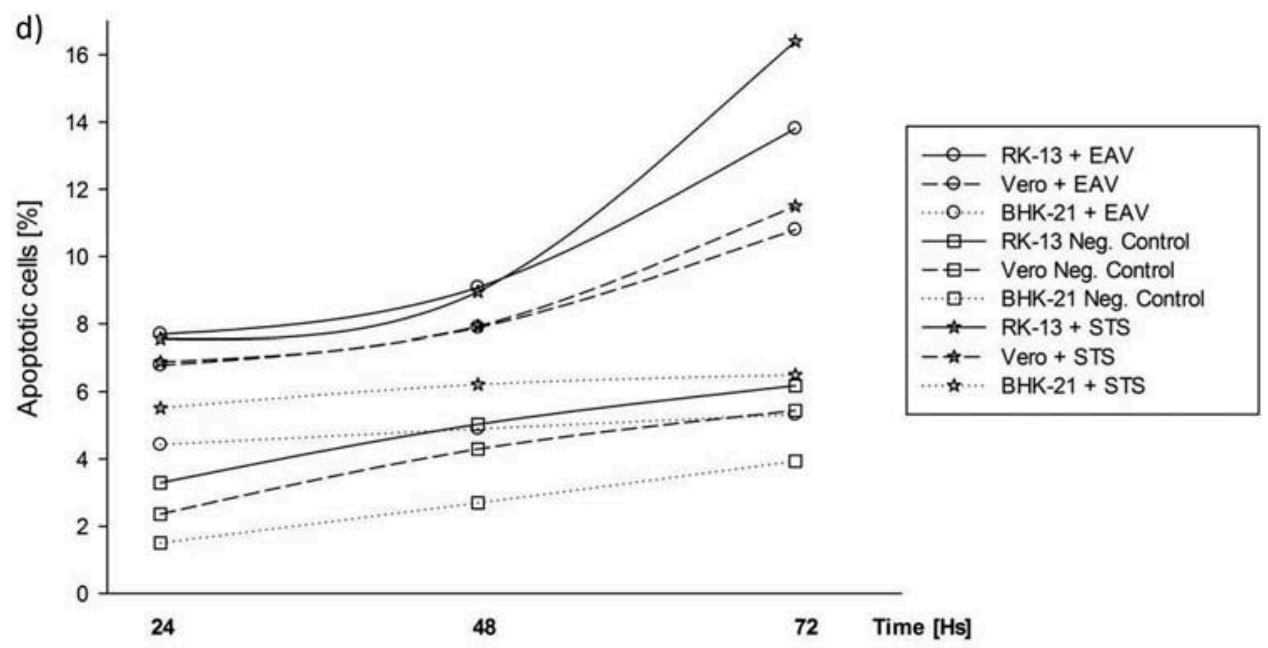

Figure 2. (Continued).

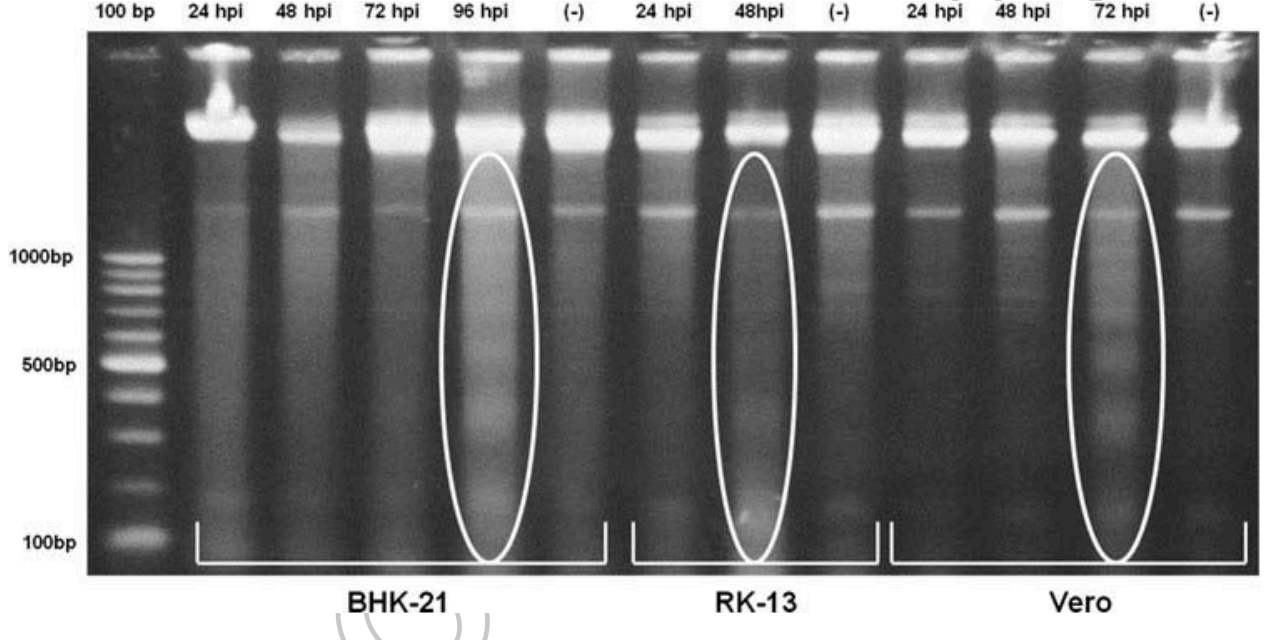

Figure 3. Agarose gel of DNA extracted from BHK-21, RK-13 and Vero cell lines infected with EAV using phenol/chloroform at different hours post-infection. DNA ladder-characteristic of the apoptosis process highlighted in circle.

Table 1. Viral titers of EAV in three cell lines at each post-infection time.

\begin{tabular}{lc}
\hline Cell lines/hpi & Virus titer (TCID $\mathbf{5 0 \% / 5 0 ~} \boldsymbol{\mu l}$ ) \\
\hline BHK-21 24 hpi & $10^{6.5}$ \\
BHK-21 $48 \mathrm{hpi}$ & $10^{6.4}$ \\
BHK-21 72 hpi & $10^{6.5}$ \\
BHK $2196 \mathrm{hpi}$ & $10^{4.2}$ \\
RK-13 $24 \mathrm{hpi}$ & $10^{4.5}$ \\
RK-13 48 hpi & $10^{4.5}$ \\
RK-13 $72 \mathrm{hpi}$ & $10^{3.6}$ \\
Vero $24 \mathrm{hpi}$ & $10^{5.8}$ \\
Vero $48 \mathrm{hpi}$ & $10^{5.5}$ \\
Vero $72 \mathrm{hpi}$ & $10^{5.3}$ \\
\hline
\end{tabular}

Titers were calculated using the Reed and Muench (1938) method.

EAV infection has been studied in many cell lines 275 (Snijder and Meulenberg; 1998; Archambault and StLaurent 2000; Zhang et al. 2008; Cholleti et al. 2013). Apoptosis caused by EAV infection has been studied mainly in three cell lines: BHK-21, RK13 and Vero cells; we also investigated these cell lines. Although EAV causes apoptosis in these three cell lines (Archambault and St-Laurent 2000; St-Louis and Archambault 2007; Cholleti et al. 2013; Metz et al. 2016), the distinctive kinetic parameters observed among experiments could not be attributed with certainty to either the cell line or to the EAV strain used.

We examined first the morphological changes in apoptotic cells. For all three cell lines, we found morphological changes in EAV infected cells that were comparable to staurosporine induced apoptotic cells. Typical blebbing of apoptotic cells and the concomitant appearance of apoptotic bodies were found in all cell samples by contrast to uninfected culture cells. The only difference among the cultured cells was that in EAV infected BHK-21 cells, the morphological features 

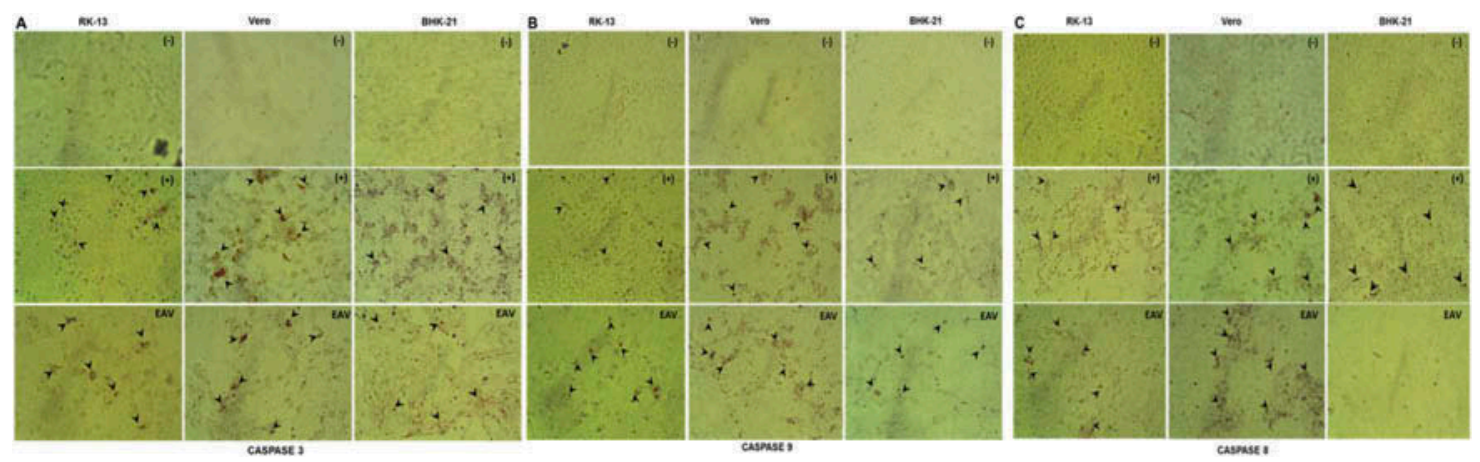

Figure 4. a) Activation of caspase-3 analyzed in situ with polyclonal caspase-3 immunostaining in RK-13 Vero and BHK-21 cells. (-) Uninfected cells (negative control); (+) staurosporine induced apoptotic cells (positive control); (EAV) EAV infected cells at 48 hpi. Arrows indicate red precipitate that indicates caspase-3 recognition. 10 x. b) Activation of caspase-9 analyzed in situ in RK-13 Vero and BHK-21 cells by caspase-9 immunostaining. (-), Uninfected cells (negative control); (+), staurosporine induced apoptotic cells (positive control); (EAV), EAV infected cells at $48 \mathrm{hpi}$. Arrows indicate red precipitate that indicates caspase- 9 recognition. $10 \mathrm{x}$ objective. c) Activation of caspase-8 analyzed in situ in RK-13 Vero and BHK-21 cells with caspase-8 immunostaining. (-) Uninfected cells (negative control); (+) staurosporine induced apoptotic cells (positive control); (EAV), EAV infected cells at 48 hpi. Arrows indicate red precipitate that indicate caspase-8 recognition. $10 \mathrm{x}$ objective.
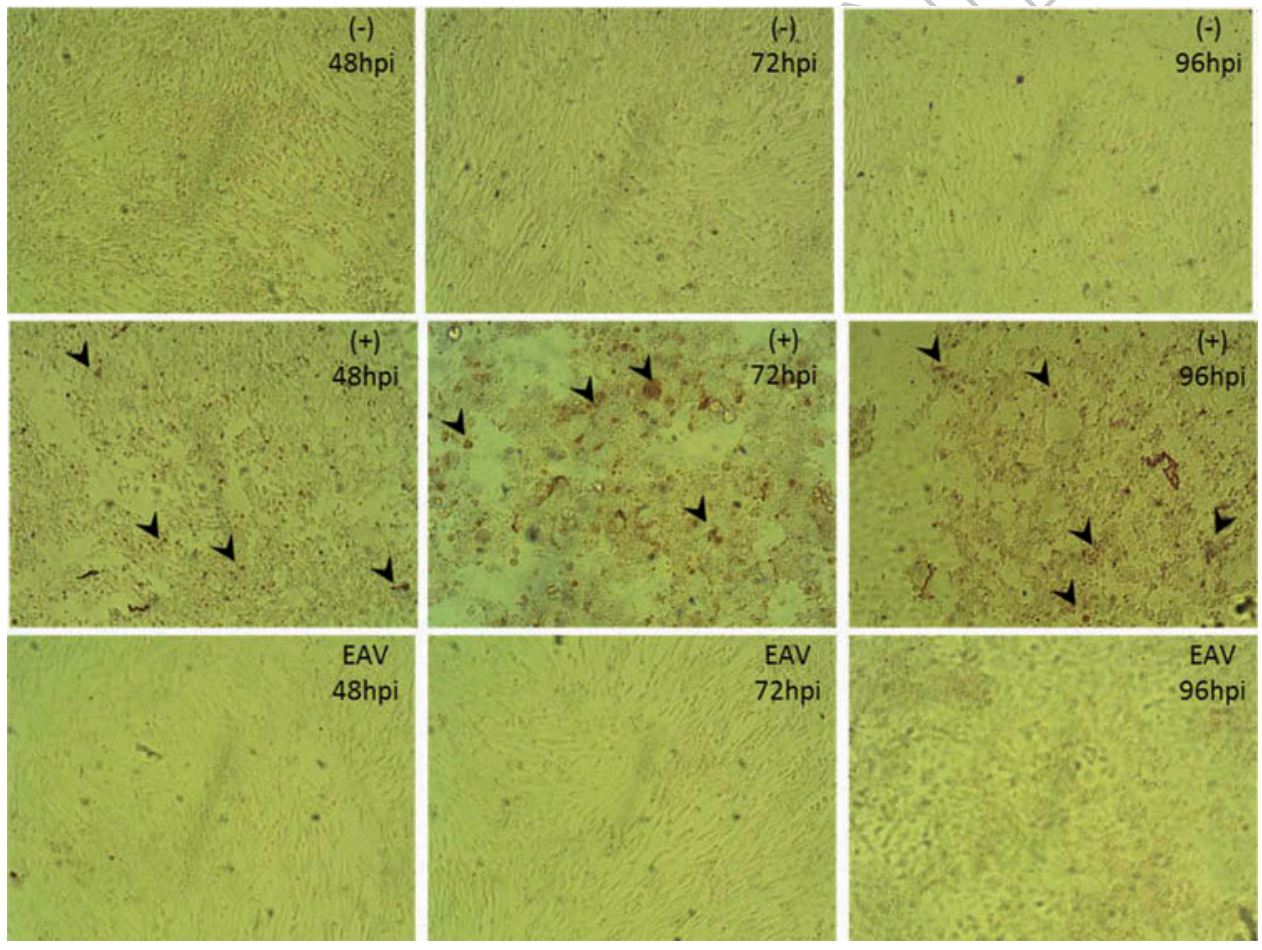

Figure 5. Time course of caspase- 8 activation analyzed in situ in BHK-21 cells with polyclonal caspase- 8 immunostaining from 48 to 96 h. (-), Uninfected BHK-21 cells (negative control); (+), staurosporine induced apoptotic BHK-21 cells (positive control); (EAV), EAVinfected BHK- 21cells. Arrows indicate red precipitate that demonstrates polyclonal caspase-8 recognition. $10 \mathrm{x}$ objective.

were found at $48 \mathrm{hpi}$, whereas in RK-13 and Vero cells, the morphological features were found at $24 \mathrm{hpi}$.

Flow cytometry enabled us to obtain quantitative results that are summarized in Figure $2 \mathrm{~d}$. The percentage of apoptotic cells found in EAV infected RK-13 and Vero cells was similar to the percentage of apoptotic cells in staurosporine-induced cell cultures (positive control) at all times assayed. By contrast, EAV infected BHK-21 cells exhibited delayed induction of apoptosis in both positive and negative controls, but the delay was more evident in EAV infected cells. Differences between $\mathrm{AO} / \mathrm{EB}$ staining and flow cytometry results for BHK-21 were due to the different sensitivity of the techniques. 
BHK-21 infected with vesicular stomatitis virus also exhibited delayed apoptosis induction compared to HeLa infected cells (Kopecky and Lyles 2003). These investigators suggested that BHK-21 infected cells may require additional, specific gene expression to initiate apoptosis in response to viruses in the cells. Induction 315 of apoptosis and the kinetics of DNA fragmentation depends on the cell line used (Kwasnik et al. 2013). We found that DNA fragmentation in infected cells showed evidence of DNA laddering at $48 \mathrm{hpi}$ in RK13, 72 hpi in Vero and 96 hpi in BHK-21 cells. Because DNA fragmentation is characteristic of the late stages of apoptosis, it is reasonable that once this occurs, the cells must die. Therefore, at 72 hpi, RK-13 cells exhibited a cytopathic effect and nearly all cells were detached; BHK-21 exhibited little cytopathic effect at 32596 hpi (data not shown). Therefore, the DNA fragmentation that we observed is consistent with our other methods for examining apoptosis, i.e., AO/EB staining and flow cytometry, and with the appearance of cytopathic effects in each cell line.

330 Pro-apoptotic viruses promote cell death to avoid an inflammatory response in infected cells (Koyama et al. 2003); therefore, induction of apoptosis by viruses may limit the time and cell machinery available for viral replication. EAV titration in infected cells showed that

335 the highest viral titers were reached at $24 \mathrm{hpi}$ in the three cell lines evaluated. Viral titers then decreased consistently with the detection of apoptosis in cells. Consequently, we hypothesized that the apoptosis blocked EAV replication, which would be consistent with the viral titers found.

Apoptosis is a fundamental biological process that all viruses must manipulate to their own benefit. EAV is a small RNA virus that replicates rather rapidly. Therefore, the kinetic difference between the rate of apoptosis and that of virus replication could explain the EAV titers that we found. The kinetics of apoptosis limits the time that viruses can use for replication (Blaho 2004). Consequently, the lower rate of apoptosis in BHK-21 cells could explain the higher EAV titers in this cell line.

350 Similarly, the lower EAV titers in RK-13 could be explained by higher rates of apoptosis for these cells.

St-Louis and Archambault (2007) reported that UV light-inactivated EAV was unable to induce apoptosis in Vero cells. Therefore, EAV replication and apoptosis 355 could be a self-regulated process; this hypothesis is controversial for the PRRSV model. Some have proposed that apoptosis occurs only in bystander cells and independent of PRRSV replication (Miller and Fox 2004), while others have proposed that apoptosis is 360 induced by PRRSV replication itself (Lee and Kleiboeker 2007; Wang et al. 2015).
Caspases are among the best characterized biochemical markers for apoptosis. Caspase- 3 is the executioner caspase in the apoptosis mechanism and caspases- 8 and -9 are indicative of the extrinsic and intrinsic apoptosis pathways, respectively. Activation of both apoptosis pathways has been reported in Vero and RK13 cells with EAV infection (St-Louis and Archambault 2007; Metz et al. 2016) and only the intrinsic pathway has been reported in BHK-21 (Cholleti et al. 2013). Activation of caspase- 3 has been reported by all investigators in the three cell lines studied here.

We confirmed activation of caspase- 3 and caspase- 9 in the three cell lines assayed. On the other hand, caspase-8 (extrinsic apoptosis pathway) was detected in only two cell lines and was not detected in BHK21 cells. Because caspase- 8 was not detected in the cell lines using EAV Bucyrus strain, we suggest that the extrinsic apoptosis pathway is not crucial for the induction of apoptosis in these cells.

Also, the absence of detection of extrinsic apoptosis in BHK-21 cells could not be linked to the pathogenicity of EAV strains, because Cholleti et al. (2013) reported the same results using different pathogenic and nonpathogenic EAV strains. Instead, we attribute the absence of the extrinsic mechanism to the general delay of apoptosis detection in BHK-21 infected cells.

Cell death by the intrinsic pathway of apoptosis is caused by the release of cytochrome $c$ from mitochondria into the cytosol and activation of caspase-9; this cascade of reactions is regulated both positively and negatively by several proteins. After an apoptotic stimulus, Smac/DIABLO is released from the mitochondria and neutralizes inhibitor apoptosis proteins (IAPs) to initiate apoptosis ( $\mathrm{Du}$ et al. 2000). Because we detected caspase- 9 in all cell cultures, we assume the concomitant activation of the intrinsic apoptosis pathway. It would be interesting to analyze Smac/DIABLO or anti-apoptotic protein balance to clarify this.

We found morphological and biochemical features of apoptosis in EAV infected cell lines that are used routinely for investigation of EAV infections using the reference pathogenic Bucyrus strain. Cell death occurred by extrinsic mechanisms in EAV infected RK-13 and Vero cells, but not in BHK-21 cells. Detection of caspase-9 activation in the three cell lines indicates activation of intrinsic mechanisms, although investigation of pro- and antiapoptotic protein balance is required for more conclusive results, EAV replication and apoptosis could be a mutually regulated process, whereas infection with EAV induces and controls the activation of apoptosis. The apoptotic mechanism affects viral replication directly. Additional investigation is required to determine the direct effect of EAV replication on development of apoptosis.
365 


\section{Acknowledgments}

The technical assistance of Ms. A. N. Conde and Mr. C. Leguizamón are highly acknowledged. GE Metz and MA Abeyá contributed equally to this work.

\section{Disclosure statement}

420 No potential conflict of interest was reported by the authors.

\section{Funding}

Our study was supported by grants from the National

\section{ORCID}

GE Metz (D) http://orcid.org/0000-0001-5098-7059

\section{References}

Archambault D, St-Laurent G. 2000. Induction of apoptosis by equine arteritis virus infection. Virus Genes. 20:143-147.

Blaho JA. 2004. Virus infection and apoptosis (issue II) an introduction: cheating death or death as a fact of life? Int Rev Immunol. 23:1-6.

Cholleti H, Paidikondala M, Munir M, Hakhverdyan M, Baule C. 2013. Equine arteritis virus induced cell death is associated with activation of the intrinsic apoptotic signaling pathway. Virus Res. 171:222-226.

de Groot RJ, Baker SC, Baric R, Enjuanes L, Gorbalenya AE, Holmes KV, Perlman S, Poon LL, Rottier PJ, Talbot PJ, Woo PCY, Ziebuhr J. 2012. Family coronaviridae. In: King AMQ, Adams EB, Lefkowitz EJ, editors. Virus taxonomy ninth report of the international committee on taxonomy of viruses. Amsterdam: Elsevier Academic Press; p. 806-828.

Du C, Fang M, Li Y, Li L, Wang X. 2000. Smac, a mitochondrial protein that promotes cytochrome c-dependent caspase activation by eliminating IAP inhibition. Cell. 7. 102:33-42.

Dunowska M, Biggs PJ, Zheng T, Perrott MR. 2012. Identification of a novel nidovirus associated with a neurological disease of the Australian brushtail possum (Trichosurus vulpecula). Vet Microbiol. 156:418-424.

Elmore S. 2007. Apoptosis: a review of programmed cell death. Toxicol Pathol. 35:495-516.

Häcker G. 2000. The morphology of apoptosis. Cell Tissue Res. 301:5-17.

Jelachich ML, Lipton HL. 1996. Theiler's murine encephalomyelitis virus kills restrictive but not permissive cells by apoptosis. J Virol. 70:6856-6861.

Kasibhatla S, Amarante-Mendes GP, Finucane D, Brunner T, Bossy-Wetzel E, Green DR. 2006. Acridine Orange/ Ethidium Bromide (AO/EB) staining to detect apoptosis. CSH Protoc. 2006(3):pdbprot4493.

Kitazumi I, Tsukahara M. 2011 Feb. Regulation of DNA fragmentation: the role of caspases and phosphorylation. FEBS J. 278(3):427-441. [Epub 2010 Dec 23].
Kopecky SA, Lyles DS. 2003. Contrasting effects of matrix protein on apoptosis in HeLa and BHK cells infected with vesicular stomatitis virus are due to inhibition of host gene expression. J Virol. 77:4658-4669.

Koyama AH, Adachi A, Irie H. 2003. Physiological significance of apoptosis during animal virus infection. Int Rev Immunol. 22:341-359.

Kuhn JH, Lauck M, Bailey AL, Shchetinin AM, Vishnevskaya TV, Bào Y, Ng TF, LeBreton M, Schneider BS, Gillis A, Tamoufe U, Diffo Jle D, Takuo JM, Kondov NO, Coffey LL, Wolfe ND, Delwart E, Clawson AN, Postnikova E, Bollinger L, Lackemeyer MG, Radoshitzky SR, Palacios G, Wada J, Shevtsova ZV, Jahrling PB, Lapin BA, Deriabin PG, Dunowska M, Alkhovsky SV, Rogers J, Friedrich TC, O'Connor DH, Goldberg TL. 2016. Reorganization and expansion of the nidoviral family arteriviridae. Arch Virol. 161:755-768.

Kwaśnik M, Rożek W, Zmudziński JF. 2013. Induction of apoptosis in MDCK RK13 and neuro -2a cells infected with equine influenza virus. Bull Vet Inst Pulawy. 57:3-7.

Lauber C, Ziebuhr J, Junglen S, Drosten C, Zirkel F, Nga PT, Morita K, Snijder EJ, Gorbalenya AE. 2012. Mesoniviridae: a proposed new family in the order nidovirales formed by a single species of mosquito-borne viruses. Arch Virol. 157:1623-1628.

Lee SM, Kleiboeker SB. 2007. Porcine reproductive and respiratory syndrome virus induces apoptosis through a mitochondria-mediated pathway. Virology. 365:419-434.

Metz GE, Galindo I, Abeyá MM, Echeverría MG, Alonso C. 2016. Intrinsic extrinsic and endoplasmic reticulum stressinduced apoptosis in RK13 cells infected with equine arteritis virus. Virus Res. 213:219-223.

Miller LC, Fox J. 2004. Apoptosis and porcine reproductive and respiratory syndrome virus. Vet Immunol Immunopathol. 102:131-142.

Nakamura-López Y, Villegas-Sepúlveda N, Sarmiento-Silva RE, Gómez B. 2011. Intrinsic apoptotic pathway is subverted in mouse macrophages persistently infected by RSV. Virus Res. 158:98-107.

Préhaud C, Lay S, Dietzschold B, Lafon M. 2003. Glycoprotein of nonpathogenic rabies viruses is a key determinant of human cell apoptosis. J Virol. 77:10537-10547.

Price GE, Smith H, Sweet C. 1997. Differential induction of cytotoxicity and apoptosis by influenza virus strains of differing virulence. J Gen Virol. 78:2821-2829.

Reed LJ, Muench H. 1938. A simple method of estimating fifty percent endpoints. Am J Hyg. 27:493-497.

Rodgers SE, Barton ES, Oberhaus SM, Pike B, Gibson CA, Tyler KL, Dermody TS. 1997. Reovirus-induced apoptosis of MDCK cells is not linked to viral yield and is blocked by Bcl-2. J Virol. 71:2540-2546.

Snijder EJ, Kikkert M, Fang Y. 2013. Arterivirus molecular biology and pathogenesis. J Gen Virol. 94:2141-2163.

Snijder EJ, Meulenberg JJM. 1998. The molecular biology of arteriviruses. J Gen Virol. 79:961-979.

St-Louis MC, Archambault D. 2007. The equine arteritis virus induces apoptosis via caspase-8 and mitochondriadependent caspase-9 activation. Virology. 367:147-155.

Suarez P. 2000. Ultrastructural pathogenesis of the PRRS virus. Vet Res. 31:47-55.

Thomson BJ. 2001. Viruses and apoptosis. Int J Exp Pathol. $82: 65-76$. 
Tyler KL, Squier MK, Rodgers SE, Schneider BE, Oberhaus SM, Grdina TA, Cohen JJ, Dermody TS. 1995. Differences in the capacity of reovirus strains to induce apoptosis are determined by the viral attachment protein sigma 1 . J Virol. 69:6972-6979.

Wang G, Yu Y, Tu Y, Tong J, Liu Y, Zhang C, Chang Y, Wang S, Jiang C, Zhou E-M, Cai X, Leung FC. 2015.
Highly pathogenic porcine reproductive and respiratory syndrome virus infection induced apoptosis and autophagy in thymi of infected piglets. PLoS One. [accessed 2015 Jun 5]. 10(6):e0128292. eCollection 2015.

Zhang J, Timoney PJ, MacLachlan NJ, McCollum WH, Balasuriya UB. 2008. Persistent equine arteritis virus infection in HeLa cells. J Virol. 82:8456-8464.

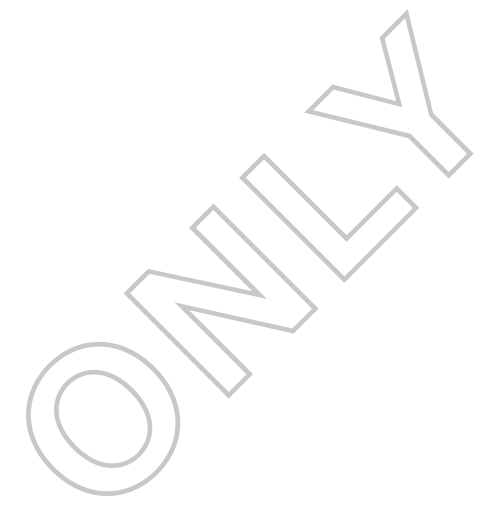

